\title{
Social design in the cultural and leisure activities of adolescents in the context of establishing additional education
}

\author{
Elena Oleynik ${ }^{1, *}$ Svetlana Ispulova $^{1}$, and Olga Potrikeeva $^{1}$ \\ ${ }^{1}$ Nosov Magnitogorsk State Technical University (NMSTU), 455000, 38 Lenin ave., Magnitogorsk, \\ Russia
}

\begin{abstract}
The article is devoted to the study of the problem of implementing a social design in the cultural and recreational activities of adolescents in the context of establishing additional education (using thr example of the adolescent club "Rovesnik" in Uchaly, Belarus). The article reviews a number of important issues in education, including scientific directions studied in the framework of this research, namelly the role of cultural and leisure activities in the formation of the personality of adolescents; social design in cultural and leisure activities; assimilation of social roles by a teenager, satisfaction of their needs in socially useful activities; self-realization of personality through participation in socially significant practical activities. The authors analyze the data of the empirical study and formulate conclusions on the problem under study.
\end{abstract}

\section{Introduction}

Teenagers spend a lot of time in front of television and computer screens, which adversely affects positive socialization and leads to the emergence of Internet addiction [1, p. 23]. Without a doubt, the Internet promotes self-education of the individual, if it is used as an educational tool. But often the Internet is referred to the sphere of leisure.

According to the first all-Russian scientific study of the digital competence of teenagers and parents of adolescent children, being conducted in 2016 by the Internet Development Fund and the Faculty of Psychology of Moscow State University named after M. V. Lomonosov with the support of the Google company in Russia, $89 \%$ of adolescents of 12 17 years old use the Internet daily. As it turned out, almost a third of the interviewed adolescents believe that the Internet is devoid of any shortcomings, and every tenth was hampered by the question of the "minuses" of the Internet. Online games and mobile games are popular for $33 \%$ of adolescent children. $92 \%$ of those surveyed use social networks for communication, replacing real communication with virtual ones. Because of the hobby of Internet slang, adolescents allow a lot of phonetic, spelling, and lexical errors in written speech, and in oral speech there is poor vocabulary when communicating, and obscene words are used in everyday life [2, p. 97-101].

* Corresponding author: oleynik.ev@ mail.ru 


\subsection{Relevance of the problem}

The urgency of the research problem is due to the socio-cultural situation in Russia at the present time, in our opinion. It is characterized by a multitude of negative factors, such as the loss of moral values, the alienation of the younger generation from culture, and the aimless pursuit of leisure [3, p. 16]. The problem of organizing cultural and recreational activities of adolescents is becoming socially important and relevant. Leisure fulfills the function of self-education and self-realization of the individual, becoming a necessary link for the adolescent's entry into the sphere of culture.

Sociologists A. I. Vishnyak and V. I. Tarasenko, considering leisure as an active activity, subdivide it into real and imaginary. Real leisure realizes personal and social goals, includes time for self-realization, entertainment, as well as useful public activities. Imaginary leisure, namely aimless pastime leads to the degradation of the person, the commission of antisocial behavior, and, ultimately, brings the damage to society [4, p. 68]. In such conditions, teenage culture is adversely affected by such tendencies as the growth of deviant behavior, the use of psychoactive substances, drug addiction, drunkenness, the crisis of moral values, the increase in suicidal moods, the increase in neglect, and the growth of infantility in the behavior of the younger generation [5, p. 489].

\subsection{Literature review}

Analysis of scientific literature has shown that at present there is a huge number of scientific works on the study of the socio-psychological characteristics of adolescents, explaining the difficulties of adolescence, different approaches have been developed to determine the boundaries of adolescence. At the same time, the concept of "leisure" has been actively studied since the 80 s of the 20 th century and has the status of a scientific problem.

In the framework of our research, we studied the following questions:

- The role of cultural and leisure activities in the formation of the personality of adolescents;

- Social design in cultural and leisure activities;

- Adoption of social roles by a teenager, satisfaction of his/her needs in socially useful activities;

- Self-realization of personality through participation in socially significant practical activities.

The basic need of adolescence is the need for self-fulfillment. In the Federal Target Program of Education for 2016-2020 there is a subprogram entitled "Involving the youth in social practice," which goal is to create conditions for successful socialization and effective self-realization of the youth. The Ministry of Youth Policy, Sport, and Tourism of the Republic of Bashkortostan sets the task of attracting young people to participate in socially significant projects oriented to the Concept of the Development of Spiritual and Moral Culture and Civic Engagement of Children, Adolescents, and Youth [6, 7].

\section{Statement of problem and methods}

The abovementioned makes it possible to talk about the existence of a contradiction between the demand among adolescents of new areas of cultural and recreational activities that meet their needs for self-fulfillment and the lack of these directions. The revealed contradiction determines the problem of research, which consists in the search and scientific justification of the means and methods of cultural and recreational activities of adolescents, meeting their preferences. 
Despite the fact that there is a significant foundation for theoretical developments, the problem of the social design of the cultural and recreational activities of adolescents has not been fully studied. To solve this problem, general scientific and special research methods should be used.

To study the problem of organizing cultural and recreational activities, we use the method of traditional analysis of documents. It is through this method that it is possible to assess the content of a social process. Authors use the tools of Sociological Science: interviewing, conversation, questioning, designing, modeling, without which it is impossible to study the social problems of contemporary society.

The method of comparative analysis is used by the authors to identify the similarities and differences in expert assessments on a number of issues, namely the quality of the organization of cultural and recreational activities in the context of the establishment of additional education, the variability of the provided classes in institutions of the type considered, the possibilities and potential consequences of introducing social design in cultural-leisure activities of adolescents, etc.

\section{Main part}

\subsection{The role of cultural and leisure activities in the formation of the personality of a teenager}

The concept of "leisure" is widely studied by many Social Sciences and is of interest to many researchers. There are different interpretations of this concept, we generalize the existing meanings of the word "leisure" [8]:

- Leisure as contemplation, associated with a high level of culture and intelligence, evaluates the effectiveness of the activity;

- Leisure as an activity not related to work, aimed at self-realization;

- Leisure eisure as a free time, time of choice;

- Leisure as all of the above.

V. T. Lisovsky believes that the formation of the personality of a teenager is influenced by such factors as the purposeful impact of society, the social environment in which the personality develops and forms, the activity of the adolescent himself, the ability to analyze, compare and classify the information obtained, and actively participate in practical transformative activities. According to the sociologist, it is precisely this quality that is lacking in modern adolescents [9, p. 108].

Adolescence is considered the period of the formation of the personality, the study of the surrounding world. During this period, the teenager bases the world outlook, morality, social attitudes, the system of value judgments, and forms the personality type [10, p. 7]. Social self-awareness is the main neoplasm of adolescence, which depends on cultural and leisure activities. Adolescent leisure differs significantly from the leisure of other categories and age groups because of the characteristic socio-psychological characteristics of adolescents and their needs. Recall that such features are heightened emotionality, frequent changes of mood, physical mobility, interest in the unknown [11, p. 512].

\subsection{Social design in cultural and leisure activities}

Social design is an effective means of organizing active cultural and leisure activities. Fundamentals of the social design in this field were developed by A. P. Markov and G. M. Birzhenyuk. The social design of cultural and recreational activities is a specific technology that represents a constructive, creative activity, the essence of which is the analysis of 
problems and the identification of the causes of their occurrence, the development of goals and objectives that characterize the desired state of the object (or the scope of project activities), the development of ways and means achievement of the set goals [12, p. 752].

The development of scientific research in the field of the social design in cultural and leisure activities involved many scientists. In the current situation, almost every cultural institution is engaged in designing, striving to improve the quality of life in society and to implement its project idea to receive funding from the state budget, from the sponsor [13, 14].

At the present stage of the development of cultural and recreational activities, many researchers singled out social design as a productive means of organizing recreational activities, contributing to the self-realization of the youth [13, p. 908]. The very social design is already a special technology for the development of social activities of young people, the organization of effective work with young people in the leisure environment. In the most general form, social design is the construction by an individual, group or organization of an action aimed at achieving a socially significant goal and localized in place, time, and resources $[13,14]$. Allocate the need to create conditions for the successful organization of leisure in the process of communication, creative interaction, collective creative activity, joint project activities.

At present, the project "All-Russian Volunteer Corps of the 70th Anniversary of the Victory in the Second World War 1941-1945," "Republican Academy of Volunteering Excellence," a project on the organization of social services for the population at home (including leisure services) and others. Advantages of design technology in comparison with other methods of targeted sociocultural changes is that it combines the normative and diagnostic approaches typical for programming and planning $[7,16]$.

\subsection{Studying the cultural and recreational needs of adolescents on the basis of the adolescent club "Rovesnik" in Uchaly}

The empirical study was aimed at studying the cultural and recreational interests and needs of adolescents, and conducted through a questionnaire. It was determined which circles teenagers prefer to visit, than would like to take their free time, as it is organized at this stage. The target sample size was 75 respondents, the children and adolescents aged 6 to 16 years.

The analysis of the primary data showed that on average pupils have 3 hours of free time a day when they can be involved in the life of the club. For most of them, free time coincides with the schedule of the club (Table 1).

Table 1. Amount of free time.

\begin{tabular}{|l|c|}
\hline \multicolumn{1}{|c|}{ Judgments } & Number of respondents (in\%) \\
\hline More than 3 hours & $36 \%$ \\
\hline From 2 to 3 hours & $36 \%$ \\
\hline Less than an hour & $12 \%$ \\
\hline Custom Variant & $16 \%$ \\
\hline
\end{tabular}

In the leisure activities of teenagers, the hobby takes an important place. In accordance with Figure 1, a large percentage of adolescents who consider their favorite occupation as a computer. We can use this habit in the right direction and apply a computer program for processing photographs, creating texts by teenagers. Children who like to draw will be able to show their talents, making wall newspapers. At the same time, dancers and singers will be able to stand out at festivities with their performances. 


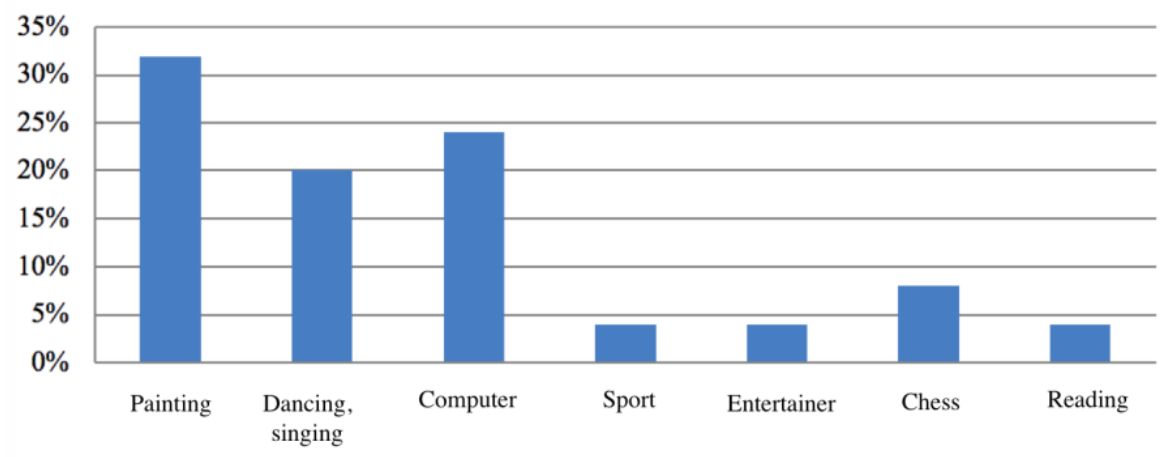

Fig. 1. Hobbies for teenagers.

In the course of the study, we also learned what children and adolescents want to learn, the results are shown in Table 2.

Table 2. Goals of adolescents.

\begin{tabular}{|l|c|}
\hline \multicolumn{1}{|c|}{ Judgments } & Number of respondents (in $\%$ ) \\
\hline Speak to the public, play on stage & $36 \%$ \\
\hline Sing & $16 \%$ \\
\hline Draw & $16 \%$ \\
\hline Dance & $16 \%$ \\
\hline Professional photography & $12 \%$ \\
\hline Playing football and tennis & $4 \%$ \\
\hline
\end{tabular}

\subsection{Results of approbation of the program for the implementation of the social design in the cultural and recreational activities of adolescents}

In modern conditions, the organization of cultural and recreational activities of adolescents has reached a new level: relying on traditional species, new models of leisure activities are being developed, various actions, flash mobs, and the activity of volunteer organizations are welcome. Such productive leisure allows the young generation to engage in socially significant affairs. In our opinion, an effective means of attracting adolescents to active leisure activities is the social design.

The purpose of our project was the active involvement of pupils of the club in the place of residence in cultural and recreational activities for their self-realization, personal development. The novelty lies in the fact that we created not just a system of leisure activities for teenagers, but improved the practice of their involvement in project activities. New directions of work with teenagers were chosen, recommendations for the project implementation were formulated. During the development of the project we were guided by such expected results:

- Introduction of new directions of cultural and leisure activities;

- The formation of a permanent group of volunteers at the club at the place of residence to provide assistance in cultural and recreational activities;

- The creation of a new methodological base for working with adolescents;

- The experience of the project team;

- Initiative of the participants to continue the project.

The target group included active pupils of the club (the project team), who participated in the organization and conduct of events of a different nature from September 2016 to May 2017, as well as took part in all competitions held by the club. In the summer (from June to 
July), juveniles who are registered with the Department of Juvenile Affairs (DJA) and the Commission for Juvenile Affairs (CJA) were included in the work. Prior to this period, they were participants in all activities, which helped them to adapt to working conditions and learn from the club's asset interaction with all project participants.

Our project consisted of three stages: preliminary, main, and final. The first stage is the preparation of the information and methodological base of the project, the development of scenarios, provisions for the conduct of events, cost planning, and budgeting. The second stage is the holding of the main events, ranging from various actions, ending with social assistance and entertainment activities. It was at this stage that the pupils actively entered the life of the club, helped the organizers to conduct competitive programs, and offered their ideas. At the final stage, the adolescents actively participated in the CJA and DJA, which contributed to their inclusion in the team and successful self-actualization.

Our project included 47 events: actions, social assistance to veterans, festive and entertaining cultural and leisure activities, round tables, meetings with psychologists, DJA inspectors, and social school teachers. The project team assisted in drafting the competition, typing, printing out copies, compiling a colorful advertisement, distributing them around the city. To ensure that the team did not feel uncomfortable and shy, we involved younger adolescents in organizing events for the first class, and for older ones - for their peers. Thus, we created a situation of success for each participant in the project team. Some helped with the preparation of requisites for events, others decorated the hall, the rest worked directly with the information part, with ads.

During the involvement of adolescents in the project activities, we identified important points. Adolescents coped well with the economic part of the project. They independently conducted two events outside the project, and they organized them in such a way that no money was needed in both cases. Adolescents are very smart, they easily make connections, if you need additional details, toys, costumes, they easily found them from their peers or from older acquaintances. Adolescents are looking for the most optimal ways to solve the problem. They quickly gather the audience, look for channels (social networks), through which you can quickly transfer information or make an announcement about the planned event. When the event is conducted by teenagers, they are able to behave with each other and communicate in their language. The teens have the best way to know the preferences of this contingent. More than that, they come up with innovative forms and methods of leisure that would be of interest to other teenagers and children.

Teenagers have mastered the basic principles of cultural and leisure activities, as evidenced by the fact that by the middle of the program, they began to improvise when carrying out activities and preparing requisites. Two successful events outside the plan strengthened the confidence of adolescents in the possibility of continuing project activities. The result: the initiative to continue the project was voiced by the adolescents themselves, there was an idea to create a circle of social design for new participants and master classes of project work. This idea was reinforced by the initiative of adolescents to develop their programs and projects.

\section{Conclusions}

Cultural and recreational activities contribute to the transfer of cultural values between generations, ensures the right of everyone to meet spiritual needs, creates conditions for developing leisure of the population, gives the right to organize amateur circles, promotes the culture of each individual, stimulates the development of social initiative and activity, uses a differentiated approach in work with different age and social groups, realizing his intellectual and creative potential. A competent organization of leisure employment is considered today as one of the components of a large work on the prevention of antisocial 
behavior of adolescents. Design solutions in the sphere of leisure activities allow improving the activity of institutions in accordance with today's tasks of sociocultural policy and the needs of clients.

Project activities in the field of leisure are among the innovative, creative activities, because it involves the transformation of reality, is built on the basis of appropriate technology, which can be unified, mastered and improved.

As part of the project, it was originally intended to involve teenagers in cultural and recreational activities organized on a project basis. At the end of the project, the participants took the initiative to continue the project activities and expressed a desire to learn social design methods. Teenagers have implemented and developed 6 mini-projects. After the implementation of these mini-projects, a group was formed to develop and implement the team project. So began the work of a circle on social design for adolescents.

\section{References}

1. V. V. Gagay, Yu. N. Bykov, Computer addiction teenagers as a social and psychological problem of our time: monograph (RIO SurGPU, Surgut, 2014)

2. G. U. Soldatova, Digital competence of teenagers and parents (Internet Development Fund, Moscow, 2013)

3. A. I. Belova, Problems of Modern Science, 10-1 (2013)

4. A. I. Vishnyak, V. I. Tarasenko, Culture of youth leisure (Higher School, Kiev, 2009)

5. O. L. Potrikeeva, N.G. Suprun, S. N. Ispulova, E. V. Oleynik, G. V. Slepukhina, A. A. Degtyarev, Man In India, 97, 11 (2017)

6. On the concept of development of spiritual and moral culture and civic activity of children, adolescents, and youth (http://docs.cntd.ru/document/935113004, 2017)

7. On the concept of the Federal Targeted Program for the Development of Education for 2016-2020: Feder. Law of 29.12.2014 No. 2765http://www.consultant.ru/document/cons_doc_LAW_173677, 2017)

8. L. A. Lyubushkina, A. F. Pavlov, Leisure activities as a means of socialization of adolescents. Achievements of modern science: a collection of materials of the XVIII International Scientific and Practical Conference, July 1, 2016 (Moscow, 2016)

9. V. T. Lisovsky, Sociology of Youth: monograph (Publishing House of St. Petersburg University, St. Petersburg, 1996)

10. E. V. Saiko, D. I. Feldstein, The World of Psychology, 4 (2007)

11. V. A. Berezina (Ed.), Culture and education of adolescents in the modern world: a collective monograph (Agency "Megapolis," Moscow, 2015)

12. G. D. Ismagilova, Science and society in an era of change: materials of the III international scientific and practical conference, Ufa, October 15-16, 2017 (Ufa, 2017)

13. V. A. Peshkov, Young Scientist, 21 (2016)

14. N. S. Rashkovetskaya, Historical and Socio-Educational Thought, 5 (2011)

15. Fundamentals of the state youth policy of the Russian Federation for the period up to 2025: Order of the Government of the Russian Federation of November 29, 2014 No. 2403-r (http://static.government.ru/media/files/ceFXleNUqOU.pdf, 2017)

16. Experience of the Republic of Bashkortostan on the transfer of powers to provide social services to the non-state sector: a pilot project for the organization of social 
services. service at home from July 3, 2014. No. 349-0 (http://saratov.gov.ru/gov/auth/mineconom/NKO/NKO_Bashkiria.pdf, 2017) 